\title{
Faces do gerencialismo em educação no con- texto da nova gestão pública
}

\author{
Marcelo Soares Pereira da Silva \\ Lorena Sousa Carvalho \\ Universidade Federal de Uberlândia
}

\section{Resumo}

O presente estudo analisa o Plano de Ações Articuladas (PAR) no contexto dos novos modelos de gestão e das políticas educacionais que vêm sendo implementados sob a égide da chamada Nova Gestão Pública (NGP) e sua perspectiva calcada no gerencialismo. Para tanto, serão discutidos os elementos que estruturam a NGP, com destaque para a dimensão da regulação, da accountability, do planejamento estratégico e do governo eletrônico e suas relações com a gestão da educação e, mais especificamente, com o PAR. Ao final, são apresentadas algumas conclusões que evidenciam o sentido do PAR frente à NGP como uma das faces do gerencialismo em educação.

Palavras-chave: Políticas educacionais. Gerencialismo. Gestão educacional.

\section{Managerialism faces in education in the context of new public managemen +}

\begin{abstract}
The present study analyses the Plan of the Articulated Actions (PAR) implanted in context of the new management models and of the educational politics under the aegis of what is called New Public Management (NPG) and its perspective from the manegerialism. For this, it will be discussed the elements in which NPG is strutured, with enfasis for the dimension of the regulation, of accountability, of the strategic planning and the electronic government and its relations with the educational management and, more specifically, with PAR. At the end, we presented some conclusions that evidence the meaning of the PAR in front of NPG as one of the managerialism faces in education.

Keywords: Educational politics. Manegerialism. Educational management.
\end{abstract}


Faces do gerencialismo em educação no contexto da nova gestão pública

\section{Caras del gerencialismo en la educación en el contexto de la nueva gestión pública}

\section{Resumen}

Este estudio analiza el (PAR) en el contexto de los nuevos modelos de gestión y las políticas educativas que se están desenvolvendo bajo los auspicios de la denominada Nueva Gestión Pública (NGP) y su perspectiva gerencialista. Para ello, vamos a discutir los elementos que estructuran la NGP, destacando el alcance de la regulación, de la accountability, de la planificación estratégica y de el gobierno electrónico y su relación con la gestión de la educación y más concretamente con el PAR. Al final, presentamos algunas conclusiones que muestran el sentido PAR ante la NGP como una faceta de el gerencialismo en la educación.

Palabras-clave: Política educativa. Gerencialismo. Gestión de la educación.

A condução das políticas públicas vem passando por importantes
212 mudanças quanto à sua implementação, gestão, monitoramento e avaliação. A busca por mais efetividade, na realização dessas políticas é, cada vez mais, reclamada por diferentes setores sociais. Nesse sentido, a perspectiva do planejamento e do controle social sobre essas políticas tem assumido contornos diversos, seja com a criação e institucionalização de orgãos e instituições que assumem essa tarefa, seja com o desenvolvimento de novos modelos e ferramentas de gestão.

Novos marcos conceituais vêm se consolidando na direção de fortalecer modelos de gestão de caráter gerencial. Princípios e diretrizes que vinham sendo construídos no campo da gestão da produção no setor privado, vão sendo, crescentemente, incorporados nos modos de se pensar e realizar a gestão pública. Planejamento estratégico, eficiência e eficácia, controle social, responsabilização, vão se consstituindo em pilares orientadores dessa nova gestão pública. Ao lado desses pilares, também a incorporação das novas tecnologias da informação e comunicação vem configurando um elemento estruturante nessa nova gestão pública, o que ajuda a compreender os contornos de governo eletrônico introduzidos por esses novos marcos. 
Na verdade, essas mudanças conceituais e metodológicas que sustentam a nova gestão pública se articulam a um contexto mais amplo de avanço do pensamento neoliberal no contexto da globalização e alcança os diversos setores das políticas públicas, inclusive o campo educacional. No caso brasileiro, tais mudanças tomam corpo e são introduzidas de modo mais sistemático no contexto da Reforma do Estado iniciada nos anos de 1990, porém adentram aos anos 2000, mesmo com o novo quadro político que assumiu o executivo federal de 2003. Nesse sentido, vários elementos da nova forma de compreender e organizar o funcionamento do Estado iniciados nos governos de Fernando Henrique Cardoso (1995-2002) tiveram continuidade e se aprofundaram nos governos de Luis Inácio Lula da Silva (2003-2010) e Dilma Vana Rousseff (2011-2014).

É pertinente, no âmbito deste estudo, analisar as bases da chamada Nova Gestão Pública (NGP), sua relação com a perspectiva do gerencialismo e do governo eletrônico e seus desdobramentos no campo da educação, especialmente a partir da institucinalização do Plano de Ações Articuladas (PAR). Nesse movimento de análise, num primeiro momento, procurar-se-à se deter nas raízes do gerencialismo para, em seguida, situar os elementos estruturantes da NGP e seus desdobramento na gestão da educação. Ao final, a preocupação de como o PAR deve ser compreendido para além de uma ferramenta de planejamento e gestão uma vez que traz, em si, nos seus fundamentos, na sua forma de organização e estruturação elementos que contribuem para aprofundar na educação pública, processos e práticas gestoriais que vêm sendo implementadas em outros setores da vida social.

\section{Reforma do Estado e neoliberalismo: o gerencialismo e suas raízes}

Nos anos de 1990, concomitante com as reformas sociais e educacionais implementadas nesse período, se delineou a chamada Reforma do Estado, o que implicou profundas mudanças no papel e nas formas de atuação do Estado frente à sociedade e deixou suas marcas até os dias atuais. $\bigcirc$ processo de Reforma do Estado brasileiro, na década de 1990, se desenvolveu no contexto da concretização da política neoliberal em diferentes países da América Latina. 
Faces do gerencialismo em educação no contexto da nova gestão pública

neoliberalismo originou-se após a II Guerra Mundial, na região da Europa e da América do Norte. Constituiiu-se em uma matriz teórica e política fortemente contra o Estado intervencionista e de bem-estar. Nos anos de 1970, se aprofundou a crise do Estado de Bem-Estar Social e, nesse contexto, os neoliberais consideravam que o caráter intervencionista que esse modelo de organização do Estado assumia, demandava muitos gastos públicos, destruía a liberdade dos cidadãos e inibia a livre concorrência. Nesse sentido, apostavam que o modelo de Estado neoliberal era a solução para a crise econômica que se vivenciava. As bases de sua política econômica, oriunda do século XX, cujos principais representantes são Hayek e Friedman, tem como princípio o estabelecimento do Estado Mínimo, ou seja, a inibição da interferência do Estado Nacional na economia e nas políticas sociais para se tornar um ente regulador. Como afirma Anderson, o neoliberalismo

Trata-se de um ataque apaixonado contra qualquer limitação dos mecanismos de mercado por parte do Estado, denunciadas como uma ameaça letal à liberdade, não somente econômica, mas também políitica (ANDERSON, 1995, p. 1).

Ainda de acordo com Anderson (1995), são características das políticas neoliberais: a contração na emissão monetária, a elevação das taxas de juros, a diminuição dos impostos sobre os rendimentos altos, a eliminação de controles sobre os fluxos financeiros, o desemprego maciço e o enfrentameto do movimento organizado dos trabalhadores por meio de uma nova legislação antissindical, o corte, nos gastos sociais, e a privatização dos serviços públicos.

A redefinição do papel do Estado na perspectiva neoliberal, a partir dos anos de 1990, se desenvolveu no contexto de reestruturação do modo de produção capitalista, tendo, como eixo central, a globalização. Nesse sentido, Gómes afirma que o neoliberalismo

[...] recupera de imediato a globalização e apresenta a competitividade no mercado mundial como objetivo e critério crucial das mudanças radicais que sustenta de longa data na política econômica e nas políticas em geral (GÓMES, 2000, p. 50).

A globalização não se deu no campo econômico, tampouco no campo político. $O$ processo de globalização se realiza no contexto do modo de produção capitalista e traz diferentes dimensões, tais como: a dimensão 
cultural, política, econômica, artística, social e educacional. Para Gómes, a globalização consiste em

[...] interconexões globais, não somente no campo econômico, mas há uma facilidade e freqüência com que informações, contaminação ambiental, migrantes, turismo, armas, imagens, ideias, doenças, criminalidade, etc., fluem através de fronteiras transnacional e global (GÓMES, 2000, p. 53).

Na verdade, a globalização não é um fenômeno novo, visto que é inerente ao capitalismo. Ela nasce e se intensifica com o próprio desenvolvimento do modo de produção capitalista. $\bigcirc$ capitalismo, enquanto modo de produção, busca, cada vez mais, alastrar o comércio internacional, intensificando o mercado global. Nesse sentido, a globalização deve ser tomada como um processo de alastramento desse modo de produção e circulação de mercadorias, buscando uma universalização da lógica capitalista no contexto da sociedade contemporânea. A ideia é de que a ampliação do comércio internacional, conforme a lei do mercado, se constituiria na fonte do desenvolvimento do processo econômico e social de todos os países.

Nesse quadro, uma nova organização de Estado se configura, havendo uma diminuição de gastos públicos, que passa a ser realizada por agências de outros setores que não o Estado. Para tanto, o Estado passa a funcionar com características do mercado, provando uma modificação no seu papel, uma vez que o setor público passou a buscar uma nova forma de organização e gestão, baseada na iniciativa privada.

A estratégia, portanto, é reformar o Estado e diminuir sua atuação para superar a crise. O mercado é que deverá superar as falhas do Estado, e assim a lógica do mercado deve prevalecer inclusive no Estado, para que ele possa ser mais eficiente e produtivo (PERONI, 2003, p. 21.

Os valores do mercado foram incluídos de diferentes formas na estrutura do Estado, por exemplo, privatização, contratação de serviços externos, taxação de serviços e, mais recentemente, parcerias entre público e privado. Tem-se um modelo de organização do Estado cada vez mais orientado pelo pragmatismo, voltado para os interesses do mercado e para a alta produtividade, a eficiência e a eficácia, dentro de um novo pacto gerencial. 
Faces do gerencialismo em educação no contexto da nova gestão pública

No Brasil, embora as ações, desenvolvidas nos governos de Collor de Melo e Itamar Franco, entre 1990 e 1994, direcionarem para o ideário neoliberal, a consolidação de políticas sustentadas nesse ideário se deu, principalmente, a partir dos governos do presidente Fernando Henrique Cardoso (1995-2002), quando se implementou o Plano Diretor de Reforma do Estado de 1995. Esse plano foi criado considerando o enfrentamento da crise econômica brasileira. Nesse plano, foram delineadas diversas mudanças aplicadas na administração pública em diferentes setores, sendo que essas reformas apresentadas tiveram reflexos nos governos subsequentes com a continuidade dos direcionamentos da política neoliberal contida no Plano Diretor.

O objetivo da Reforma do Estado brasileiro, segundo o Plano Diretor era

[...] reforçar a governança - a capacidade de governo do Estado - através da transição programada de um tipo de administração pública burocrática, rígida e ineficiente, voltada para si própria e para o controle interno, para uma administração pública gerencial, flexível e eficiente, voltada para o atendimento do cidadão (BRASIL, 1995, p. 13).

Além do mais, o Plano Diretor trazia algumas perspectivas para a atuação do Estado a partir da redefinição de seu papel.

Estado reduz seu papel de executor ou prestador direto de serviços, mantendo-se, entretanto, no papel de regulador e provedor ou promotor destes, principalmente dos serviços sociais como educação e saúde, que são essenciais para o desenvolvimento, na medida em que envolvem investimento em capital humano (BRASIL, 1995, p. 13).

Estado passaria a não ser mais fomentador de benefícios públicos e assumiria outro papel, como o de gerenciar, induzir e regular as políticas. Assumiria, então, um novo tipo de perfil: o gerencialismo. Tem-se, desse modo, um processo combinado de diminuição do Estado e ampliação da sociedade civil (VIEIRA, 201 1). Castro, ao caracterizar o gerencialismo, destaca que

A gestão gerencial caracteriza-se pela busca da eficiência, pela redução e pelo controle dos gastos públicos, pela demanda de melhor qualidade dos serviços públicos, pelos modelos de 
avaliação de desempenho, por suas novas formas de controlar o orçamento e os serviços públicos e pela descentralização administrativa, que dá maior autonomia às agências e aos departamentos. Além do mais, o gerencialismo ou gestão gerencial também tem como características a redução e o controle dos gastos públicos e o modelo de avaliação por desempenho - que será fundamental no âmbito educacional (CASTRO, 2008, p. 3).

Estado assume um caráter gerencialista e, nessa perspectiva, objetiva priorizar a busca da eficiência e eficácia, reduzir gastos com o setor público, além de controlar e introduzir modelos de avaliações que focam o desempenho individual, visando aferir o produto e instalando a competitividade e a descentralização como pilares dessa eficiência e eficácia.

Segundo Machado (1994, p. 20), "[...] o gerenciamento constitui a base do controle da qualidade total, pois visa não só estabelecer e manter, mas melhorar os padrões." Ainda de acordo com a autora, existem dois tipos de gerenciamento: gerenciamento pela organização ou de rotina e gerenciamento interfuncional. $\bigcirc$ primeiro tem como objetivo o controle das tarefas cotidianas, por meio de processos repetitivos. Esse nível de gerenciamento requer planejamento e execução. $\bigcirc$ segundo tipo visa à construção da visão da organização, de seus objetivos estratégicos, tendo em vista a melhoria dos processos e o enfrentamento da competição.

Esse novo tipo de administração e gestão passa a ser o alicerce da nova organização do Estado que se configurou no final do século XX e princípio do século XXI, articulado também aos processos de reestruturação produtiva e de mudanças no mundo do trabalho e da produção. Essa perspectiva de organização do Estado dissemina a ideia de que tudo o que é ruim provém do setor público e, em contrapartida, os padrões de eficiência, de qualidade e sucesso estariam na esfera privada, nas empresas e no mercado.

No contexto do gerencialismo, a lógica do mercado se inseriu, cada vez mais, nos espaços públicos, num proceso em que o setor público tem incorporado na sua dinâmica de funcionamento aspectos da cultura empresarial competitiva. Têm-se, dessa forma, as bases do gerencialismo que irá orientar a reorganização do trabalho, tanto no setor produtivo, no mundo da produção e circulação de mercadorias, quanto na organização e funcionamento do Estado no contexto da globalização e do avanço do ideário neoliberal. 
Faces do gerencialismo em educação no contexto da nova gestão pública

Por seu turno, o aprofundamento do gerencialismo no quadro da Reforma do Estado, conduzida no Brasil a partir do final dos anos de 1990 e que se estendeu ao longo deste século XXI, possibilita demarcar as bases, os fundamentos, estratégias e instrumentos da Nova Gestão Pública (NGP) compreendida enquanto uma das faces do gerencialismo na organização e funcionamento do Estado na atualidade, e seus desdobramentos no campo da gestão da educação.

\section{A Nova Gestão Pública e a perspectiva gerencial no processo de regoranização do Estado e a gestão da educação}

Sob a égide do pensamento neoliberal, a NGP também preconiza que os serviços públicos devem ser realizados pela iniciativa privada, em condições de livre-mercado, pois, em tese, essa medida aumentaria a eficiência dos processos de trabalho. Nesse sentido, essa proposta favorece a privatização dos serviços públicos, tendo em vista que os neoliberais consideram que este é o caminho mais eficiente e satisfatório. Nesse sentido, ela não representa 218 um corte total do modelo já existente da forma de atuação do Estado, mas procura constituir instrumentos que deem conta das necessidades contemporâneas de modificar o papel do Estado. Embora algumas características presentes na NGP não sejam inéditas, tais como o interesse pela eficiência, o controle e métodos gerenciais, existem alguns elementos e aspectos que vão além.

De acordo com Paula (2005), foram estabelecidas medidas organizativas e administrativas, atribuindo características à Nova Gestão Pública. Dentre elas, destacam-se:

- descentralização do aparelho de Estado, que separou as atividades de planejamento e execução do governo e transformou as políticas públicas em monopólios dos ministérios;

- privatização das estatais;

- terceirização dos setores públicos;

- regulação estatal das atividades públicas conduzidas pelo setor privado;

- uso de ideias e ferramentas gerenciais advindas do setor privado (PAULA, 2005, p. 47). 
Em face desses apontamentos, na NGP, foram difundidas ideias como a superioridade do setor privado em relação ao setor público; a proposição de soluções técnicas e práticas administrativas formuladas no mundo empresarial aplicadas em instituições públicas; o ideal da produtividade; a pressão pela eficiência; a busca pela excelência por meio da regulação e do controle e, ainda, a crença em tecnologias gerenciais que permitiriam as atividades organizadas.

Segundo as diretrizes da Nova Gestão Pública, os serviços públicos delegados aos setores privados ofereceriam mais resultados, seriam mais eficientes e satisfatórios, o que conduziria à crescente privatização dos serviços públicos. A delegação dessas responsabilidades para o setor privado tem como um de seus desdobramentos a consolidação de mecanismos de regulação por parte do Estado, sobre os serviços prestados.

Em suma, Nova Gestão Pública significa uma perspectiva de organização e funcionamento do Estado que tem, como pilares, a atenção focada nos resultados, verificando se há eficiência, qualidade e eficácia dos serviços; gestão descentralizada; criação de ambientes competitivos dentro das instituições públicas; objetivos claros de produtividade e subornação do controle social.

Nesse contexto, se configurou, no quadro da NGP, as agências reguladoras como entes do Estado com papel de realizar a tarefa de controle sobre os serviços.

A questão da regulação é mais amplamente discutida na área da economia, no entanto ela abrange diversos setores da sociedade. Oliveira (2005, p. 755) ressalta que a ideia da regulação "[...] alcança todos os setores, envolvendo desde a regulação da energia, dos meios climáticos, dos alimentos, dos meios de comunicação, entre outros serviços essenciais, até a imprensa."

Na perspectiva de Maués (2009), a regulação é o processo de produção de regras e de orientações das condutas dos atores. Assim, a regulação representa um conjunto de mecanismos que vão permitir o controle, buscando manter o equilíbrio e orientar as ações dos sujeitos.

Barroso (2005) considera que a regulação está relacionada, simbolicamente, com a forma de intervenção do Estado na condução das políticas públicas. Nesse sentido, o Estado assume o papel de regulador. Segundo o autor, 
Faces do gerencialismo em educação no contexto da nova gestão pública

[...] a regulação é o oposto da regulamentação, uma vez que a primeira é mais flexível na definição dos processos e rígida na avaliação da eficiência e eficácia dos resultados, enquanto que a segunda é centrada na definição e controle a priori dos procedimentos e, relativamente, indiferente às questões da qualidade $e$ eficácia dos resultados (BARROSO, 2005, p. 727).

Nesse sentido, o sistema educacional também começou a sofrer mudanças, simultaneamente, à nova regulação das políticas educacionais. A escola pública, como agência estatal, é objeto da nova regulação; por isso, sofre algumas alterações como, por exemplo, nos currículos, nas formas de avaliação e na organização do trabalho escolar. Segundo Afonso (2005) e Valente (201 1), o Estado Avaliador e, consequentemente, o Estado Regulador, está presente de várias formas na realidade educacional, mas, principalmente, nas avaliações externas.

Atualmente a avaliação tem-se configurado como um dos principais eixos da regulação da educação, uma vez que se constitui em mecanismo de controle de distribuição de recursos, pois o Estado tem atrelado o financiamento aos resultados dos índices alcançados nos testes (VALENTE, 201 1, p. 96).

Com efeito, as políticas educacionais implementadas, ao longo das duas últimas décadas, se sustentaram na lógica da regulação. A avaliação tem se configurado como um dos principais eixos da regulação da educação. Por sua vez, os parâmetros e instrumentos de avaliação adotados seguem a lógica do quase mercado, pois coloca em destaque princípios e critérios de eficiência, produtividade e competitividade, priorizando a aferição pontual do desempenho dos alunos. Privilegiam os produtos e os resultados em detrimento dos processos de construção. Nesse sentido, não consideram os fatores que estão intrínsecos à escola e as classificam em função do mérito. A questão da qualidade fica subordinada à lógica competitiva e considera, apenas, os aspectos quantitativos. A esse respeito, Hypolito assevera que

que deve ser ressaltado nessas políticas é a centralidade nos aspectos econômicos em detrimento dos aspectos políticos e sociais, como deslocamento da educação para a esfera do econômico e dos modelos gerenciais apregoados pelo mercado, como já assinalado anteriormente. O que deveria ser pressuposto de qualidade para a educação pública, garantida pelo Estado, passa a 
ser considerado como deficiência dos usuários. Em outras palavras, o que era considerado como direito do cidadão e dever do Estado passa a ser considerado como possibilidade de escolha, a partir do que é mensurado como eficiente ou ineficiente (HYPOLITO, 2010 , p. 1344).

Oliveira (2001), Oliveira (2005), Hypolito (2010) e Valente (2011) demonstraram que, nos anos de 1990, as políticas públicas educacionais foram geridas de forma racional, seguindo concepções dos organismos internacionais, dentre eles, o Banco Mundial, vinculando a educação ao desenvolvimento econômico. Nesse sentido, as tendências dos órgãos privados influenciaram, de forma significativa, na educação, prescrevendo políticas com caráter instrumental, técnico, racional, operacional, tornando as instituiçõs educativas prestadoras de serviços e o aluno seu cliente.

Concominante à perspectiva da regulação, a NGP estava baseada, também, no princípio de accountability. A accountability teve origem na Inglaterra e nos Estados Unidos e tem sido traduzida no Brasil sob a ótica de responsabilização. A utilização dessa concepção vem se desenvolvendo, desde os anos de 1990, e se consolida na condução das políticas públicas em geral e no campo da educação em particular.

Para Afonso (2009), accountability sugere uma gama de significados, remetendo as palavras políticas, sistemas, modelos, dimensões, agências, práticas e actores. Em seu estudo, Afonso (2009), esclarece que o termo accountability abrange

[...] três dimensões estruturantes: uma de informação, outra de justificação e uma outra de imposição ou sanção. Num entendimento mais imediato, a prestação de contas pode ser o pilar que sustenta ou condensa as duas primeiras: o direito de pedir informações e de exigir justificações - sendo que, para a concretização de ambas, é socialmente esperado que haja a obrigação ou o dever (regulamentados legalmente ou nãol de atender ao que é solicitado. Informar e justificar constituem assim duas dimensões da prestação de contas, a qual pode, assim, ser definida, em sentido restrito, como obrigação ou dever de responder a indagações ou solicitações (answera-bility) (AFONSO, 2009. p. 59, grifos no original).

Dessa forma, as ações proferidas são pensadas e repensadas seguindo um padrão de eficiência com vistas ao êxito cotidiano. A política de accountability é, portanto, uma política de responsabilização. 
Faces do gerencialismo em educação no contexto da nova gestão pública

A responsabilização está intimamente associada à prestação de contas, uma vez que ser responsável por um processo ou um resultado implica - sobretudo no setor público em uma sociedade democrática - em ter que prestar contas dos resultados e do uso dos recursos aplicados (VIDAL; VIEIRA, 2011 , p. 425).

A adoção da accountability (ou responsabilização) no Brasil contribuiu para as mudanças no modelo de gestão burocrática para uma administração de caráter gerencial. Nesse processo, tem-se a adoção da descentralização para garantir a eficácia e a eficiência das políticas públicas, acompanhado do processo de responsabilização, transferência de responsabilidades, prestação de contas e transparência.

A accountability é, pois, sinônimo de responsabilização e prestação de contas e está associada às abordagens e perspectivas das políticas gerenciais. Seu "[...] significado indica frequentemente uma forma hierárquico-burocrática ou tecnocrática e gerencialista de prestação de contas" (AFONSO, 2012, p. 472).

No campo educacional, a accountability pode ser caracterizada como uma transferência de responsabilidade da manutenção das escolas, por

222 meio da captação de recursos financeiros pelos próprios responsáveis e não mais dependendo do subsídio governamental, bem como a sua concorrência no mercado estabelecida pelas avaliações em larga escala e, consequentemente, o seu "rankeamento." A escola é cada vez mais responsabilizada pelo seu sucesso ou seu fracasso, uma vez que os governos consideram os recursos disponibilizados suficientes para que progridam e se desenvolvam.

Outro componente da NGP, com raízes nas empresas privadas, é o planejamento estratégico, como forma de garantir maior eficiência, eficácia e controle no alcance dos resultados esperados. $\bigcirc$ planejamento estratégico se expandiu na segunda metade do século XX e passou a ser fortemente utilizado na área de administração e gestão de empresas, no âmbito dos grupos e instituições privadas.

O planejamento estratégico, conforme Parente Filho (1991), é um processo gerencial que possibilita ao executivo estabelecer o rumo a ser seguido pela empresa, com vistas a obter um nível de otimização na relação da empresa com o seu ambiente. Parente Filho ressalta que 
No campo empresarial, o planejamento estratégico é direcionado para a ampliação da competitividade da empresa, como condição para sua sobrevivência e desenvolvimento em um ambiente de rápidas e inesperadas mudanças (PARENTE FILHO, 2001, p. 30).

Trata-se de uma ferramenta gerencial que apresenta um diagnóstico da situação atual, a identificação da missão e valores, projeta uma pretensão futura (visão de futuro), composta com objetivos estratégicos, que, por sua vez, são reduzidos a metas (objetivos quantificados). Campos (1992, p. 68) explica que "[...] o Planejamento Estratégico é, pois, um conjunto de atividades necessárias para se determinar as metas (visão), os métodos (estratégia) e o desdobramento destas metas e métodos."

planejamento estratégico se apresenta como modelo de um planejamento com aspecto técnico-racional. Ele simplifica ao extremo os objetivos a serem alcançados, o processo e as diferentes etapas do planejamento, pondo em destaque o aspecto técnico deixando de considerar, na devida dimensão, os aspectos políticos, culturais e filosóficos. Na perspectiva do planejamento estratégico, apenas os gestores e/ou administradores são responsáveis pelo processo de planejamento e definição dos objetivos. Ademais, os processos de tomadas de decisões organizacionais devem ser pautados na eficácia. Essa afirmação se comprova na passagem de Saldanha, na qual relata que

planejamento estratégico, que se reflete no todo de uma organização, tende a ser responsabilidade dos diretores e presidentes. Nele, serão tomadas decisões presentes que irão produzir efeitos futuros, os quais poderão ser positivos ou negativos, dependendo exclusivamente de um planejamento abrangente e de uma decisão acertada (SALDANHA, 2006, p. 30).

As análises, as decisões e o acompanhamento ficam centralizados nas mãos da gerência e o processo de execução é incumbência dos demais segmentos da instituição, limitando, assim, os espaços de participação no processo. Portanto, no planejamento estratégico, as decisões são tomadas pelos níveis superiores da gestão e/ou administração e, após aprovadas, são impostas aos demais segmentos.

Parente Filho (200 1) destaca ainda que um dos princípios básicos que orientam as ações no planejamento estratégico é a abordagem sistêmica. 
Faces do gerencialismo em educação no contexto da nova gestão pública

planejamento estratégico como abordagem sistêmica tem como referência inicial a missão da organização. Com base em um processo participativo de conhecimento e análise dos pontos fortes e dos pontos fracos internos à organização e do estudo das oportunidades e restrições do ambiente externo, estabelece estratégias, ou seja, os meios e ações integradas de longo prazo, que visam alcançar os objetivos e metas estabelecidas para o cumprimento da missão da organização (PARENTE FILHO, 2001 , p. 44).

Segundo a autor, a abordagem sistêmica do planejamento estratégico impõe, no momento dos estudos e das análises, a consideração, em primeiro lugar, das questões internas e externas da organização (ou setor). Além do mais, para se realizar o PE, exige-se um diagnóstico prévio dos pontos fortes e pontos fracos da instituição, exigem-se descentralização e divisão de responsabilidades e atribuições e, sobretudo, a interação com parceiros e beneficiários.

Esse tipo de planejamento apresenta algumas limitações, uma vez que atribui, como função principal, atender às necessidades do sistema econômico e, principalmente, porque parte de análises quantitativas de necessidades específicas.

Nessa perspectiva, Parente Filho, ao situar o planejamento estratégico na educação, chama a atenção para o fato de que:

[...] o predomínio de abordagens técnicas, fundamentadas em modelos originários da economia, influenciaram o planejamento estratégico, imprimindo formas e conteúdos predominantemente técnicos aos processos de planejamento, negligenciando a natureza política e os aspectos culturais e institucionais da atividade educacional (PARENTE FILHO, 2001, p. 20).

A aplicação do Planejamento Estratégico no campo educacional se deu como uma tentativa de introduzir mudanças organizacionais e gerenciais capazes de provocar melhorias. No entanto, seu caráter burocrático tem conduzido a processos de organização da prática educativa que não contribui para se alcançar avanços substantivos na qualidade da educação.

Outro pilar que sustenta a Nova Gestão Pública é o processo de consolidação do chamado governo eletrônico. $\bigcirc$ governo eletrônico se configura a partir da diversidade de mecanismos de disseminação de informação que as instâncias governamentais disponibilizaram por meio da tecnologia, utilizando-se de ferramentas, portais, sistemas e plataformas eletrônicas virtuais. 
Para Agune; Carlos (2005); Osbourne (1997), em alguns casos, a definição de governo eletrônico está vinculada às tentativas de modernização da administração pública e à melhoria da eficiência dos processos operacionais e administrativos do governo. Por sua vez, Ronaghan (2002) e Medeiros (2004) afirmam que essa definição está claramente associada ao uso da Internet, pelo setor público, para prestação de serviços públicos de forma eletrônica.

Medeiros e Guimarães (2004) sintetizam alguns conceitos de governo eletrônico ligados a três áreas de conhecimento: políticas públicas, gestão e comportamento organizacional e tecnologia da informação, como apresentado no Quadro 1 que se segue:

\section{Quadro 1}

\begin{tabular}{|l|c|}
\hline \multicolumn{1}{|c|}{ Definições de Governo Eletrônico } & Fonte \\
\hline $\begin{array}{l}\text { Governo Eletrônico refere-se ao uso, por agências governamen- } \\
\text { tais, de tecnologias de informação (como redes de longa dis- } \\
\text { tância, Internet e computação móvell) capazes de transformar as } \\
\text { relações com cidadãos, empresas e outras unidades do governo. } \\
\text { Essas tecnologias podem servir a diferentes fins, como: melhor } \\
\text { prestação de serviços aos cidadãos, interações mais eficazes } \\
\text { com empresas e a indústria, empowerment do cidadão por meio } \\
\text { do acesso a informações ou mais eficiência na administração } \\
\text { governamental. }\end{array}$ & $\begin{array}{c}\text { Banco Mundial } \\
{[\ldots]}\end{array}$ \\
\hline $\begin{array}{l}\text { Governo eletrônico ou e-governo significa prover acesso público } \\
\text { via Internet a informações sobre os serviços oferecidos pelos de- } \\
\text { partamentos centrais do governo e suas agências, habilitando o } \\
\text { público à condução e conclusão de transações para tais serviços. }\end{array}$ & National Audit \\
\hline $\begin{array}{l}\text { O termo 'e-government' [utilizado em inglês para denominar o } \\
\text { governo eletrônico] aborda o uso de novas tecnologias de infor- } \\
\text { mação e comunicação pelos governos, aplicadas a todas as suas } \\
\text { funções. }\end{array}$ & OCDE [...] \\
\hline $\begin{array}{l}\text { E-governo é definido como: utilização da Internet e da web para } \\
\text { ofertar informações e serviços governamentais aos cidadãos. }\end{array}$ & Nações Uni- \\
\hline $\begin{array}{l}\text { O termo governo eletrônico é definido como a oferta e troca } \\
\text { de informações e serviços governamentais on-line para cidadãos, } \\
\text { empresas e outras agências governamentais. }\end{array}$ & INTOSAl [...] \\
\hline $\begin{array}{l}\text { Governo eletrônico refere-se a processos e estruturas relativos ao } \\
\text { fornecimento eletrônico de serviços governamentais ao público. }\end{array}$ & Okot-Uma [...] \\
\hline
\end{tabular}

Fonte | Medeiros e Guimarães (2004) 
Faces do gerencialismo em educação no contexto da nova gestão pública

Por certo, o governo eletrônico se refere ao desenvolvimento de ferramentas gerenciais informatizadas que possibilitam ao governo e aos gestores públicos terem uma consitente base de dados eletrônicos por meio da rede mundial de computadores. Isso possibilita aos órgãos de governo um controle crescente de informações e processos gerenciais, ao mesmo tempo que possibilita integração dessas ferramentas.

Essas ferramentas e mecanismos estão ligados à incorporação das Tecnologias de Informação e Comunicação (TICs), nos termos formulados por Ramos (2008), nos processos de planejamento, controle, monitoramento e avaliação.

Chamamos Tecnologias de Informação e Comunicação (TIC) aos procedimentos, métodos e equipamentos para processar informação e comunicar que surgiram no contexto da Revolução Informática, Revolução Telemática ou Terceira Revolução Industrial, desenvolvidos gradualmente desde a segunda metade da década de 1970 e, principalmente, nos anos 90 do mesmo século. Estas tecnologias agilizaram e tornaram menos palpável o conteúdo da comunicação, por meio da digitalização e da comunicação em redes para a captação, transmissão e distribuição das informações, que podem assumir a forma de texto, imagem estática, vídeo ou som. Considera-se que o advento destas novas tecnologias e a forma como foram utilizadas por governos, empresas, indivíduos e sectores sociais possibilitaram o surgimento da Sociedade da Informação (RAMOS, 2008, p. 5).

Em outras palavras, com a ascensão da Internet e das inovações em comunicações e informações, as organizações governamentais tiveram a possibilidade de migrar seus sistemas existentes em recursos convencionais para sistemas e plataformas com interface nas TICs. Os instrumentos ligados às TICs ampliaram a possibilidade de disponibilizar informações públicas e, portanto, deram origem ao que passou a ser chamado de Governo Eletrônico.

governo eletrônico, por meio do uso das TICs, desenvolve sistemas e ferramentas no qual é possível encontrar inúmeras informações, dados e demandas relativas a uma instituição. Estas informações são disseminadas rapidamente e os gestores públicos possuem acesso aos dados disponibilizados por meio da Internet. 
A disseminação da gestão de governo eletrônico tem como eixo central, a utilização das TICs visando possibilitar o acesso rápido às informações sociais e incrementar a prestação de serviços públicos com vistas a se alcançar mais eficiência e efetividade das políticas sociais públicas.

Medeiros e Guimarães (2004) destacam que há, pelo menos, dois fatores que têm motivado governos a elaborar e utilizar sistemas baseados na Internet:

(1) a necessidade de as administrações aumentarem sua arrecadação e melhorar seus processos internos - 'fazer mais com menos' - e (2) as pressões da sociedade para que o governo otimizasse seus gastos e atuasse, cada vez mais, com transparência, qualidade e de modo universal na oferta de serviços e provimento de informações aos cidadãos e organizações em geral (MEDEIROS; GUIMARÃES, 2004, p. 50).

Complementam, enfatizando mais seis motivos para os governos aplicarem projetos e programas na perspectiva do governo eletrônico, como:

(1) 'estar presente', ou seja, assegurar sua visibilidade na sociedade; (2) mostrar exemplo aos demais atores da Sociedade da Informação; (3) prestar informações de maneira mais eficaz; (4) oferecer serviços de forma virtual; (5) permitir a consulta aos cidadãos e (6) facilitar a participação na formulação das políticas públicas (MEDEIROS, 2004, p. 32).

Prado e Pó (2010) lembram que o governo eletrônico se concretizou ancorado em dois movimentos ao longo dos anos 1990:

[... a busca de modernização da administração pública e melhoria da eficiência dos processos operacionais e administrativos do governo e o uso da Internet pelo setor público para prestação de serviços públicos de forma eletrônica (PRADO; PÓ, 2010, p. 7).

Esses movimentos e as Tecnologias de Informação e Comunicação (TICs) foram incorporadas aos processos governamentais contemporâneos no movimento de Reforma do Estado. Isso fez com que princípios gerenciais, como desempenho, eficiência, eficácia, excelência, otimização, qualidade do gasto público, transparência, prestação de contas e controle social, tomassem 
Faces do gerencialismo em educação no contexto da nova gestão pública

preocupação central no desenvolvimento de programas de governo eletrônico (PRADO; PÓ, 2010).

O governo eletrônico está atrelado à perspectiva do Estado Gerencial, bem como aos paradigmas da Nova Gestão Pública, uma vez que os seus programas e ações estão voltados à prestação de contas e à concessão de recursos financeiros para atingir as metas e objetivos definidos e/ou acordados nas políticas públicas. As novas tecnologias e os sistemas em rede permitem que a gestão pública tenha acesso cada vez mais rápido, falicilitando, assim, os dados, demandas, informações e necessidades de instituições sociais.

Por outro lado, essas ferramentas gerenciais vinculadas às TICs corroboram a responsabilização e a transparência do governo, ou a também chamada accountability, uma vez que todas as ações e programas governamentais estão disponibilizados on-line e, assim, contribuem, também, para o controle social dos cidadãos, ou seja, os cidadãos também têm acesso às informações e transações das instituições políticas. Nesse sentido, Prado e Pó (2010, p. 2) asseveram que "[...] com tais mecanismos operacionais, os cidadãos passam a ter maiores possibilidades de decidir e responsabilizar os agentes políticos por seus atos ou omissões." Sendo assim, essas ferramentas 228 on-line estão a serviço tanto do governo e das instituições políticas para controle e monitoramento, quanto da população que pode ter acesso aos serviços públicos prestados. Prado e Pó observam que

Dessa forma, os programas de governo eletrônico assumiram uma posição privilegiada para a promoção de processos mais abertos e transparentes de governança, com a disponibilização de informações por parte dos governos e dos diversos atores, assim como de mecanismos de participação e opinião dos governados nos processos políticos. Representantes eleitos e a burocracia governamental, protagonistas centrais de decisões políticas relevantes para toda a sociedade, ficariam, assim, mais permeáveis ao seu escrutínio e opinião da sociedade. Daí, é quase obrigatório inferir que o governo eletrônico pode tratar de um aperfeiçoamento da própria democracia (PRADO; PÓ, 2010, p. 5).

Dessa forma, o Governo Eletrônico, por meio da Internet, se constituiria um veículo de aproximação e comunicação entre Estado e sociedade/ governo e cidadão. Consoante com essa ideia, Medeiros e Guimarães ressaltam que 
A Internet, como veículo de aproximação do Estado com o cidadão, é o principal instrumento para a consecução dos planos de fazer o governo cada vez mais 'eletrônico'. A intenção, com a presença governamental na web, é tornar o aparato administrativo menos aparente de forma presencial, mas, ao mesmo tempo, mais próximo do cidadão e mais eficiente na realização de seus objetivos, com a utilização de técnicas e sistemas de informática e comunicações. Com isso, verifica-se a utilização de TIC na implementação de conceitos contemporâneos advindos da administração, a exemplo do gerencialismo na condução das organizações públicas, e mesmo um incentivo ao controle social (MEDEIROS; GUIMARÃES, 2004, p. 50).

Governo eletrônico, planejamento estratégico, accountability, responsabilização, controle social, regulação definem, pois, os contornos da NGP e seus desdobramentos na organização do Estado e das políticas públicas em geral e na educação em particular. Por certo, se, por um lado, esses elementos podem contribuir para se alcançar maior agilidade e transparência na gestão pública; por outro lado, à medida que se orientam e estruturam sob a égide da perspectiva gerencialista sustentada pelas teorias e métodos de administração capitalista, pouco podem fazer naquela direção.

No campo educacional brasileiro, o Ministério da Educação tem criado mecanismos de monitoramento e acompanhamento permanente de todas as ações de diferentes municípios, estados e Distrito Federal. Diversas ferramentas gerenciais têm sido implementadas na perspectiva da Nova Gestão Pública (NGP). Estas ferramentas podem permitir um controle sistemático e articulado do desempenho de cada rede e unidade de ensino, ao mesmo tempo que podem contribuir para o controle social e de prestação de contas do governo, como é o caso do Plano de Ações Articuladas (PAR).

\section{O PAR: sua estrutura e organização}

PAR se constitui em uma ferramenta de planejamento estratégico e está estruturado em torno dos quatro eixos de ação preconizados no Decreto n 6.094 , de 24 de abril de 2007, de modo que, no instrumento de organização desse Plano, o ente federado deverá considerar quatro dimensões: 
Faces do gerencialismo em educação no contexto da nova gestão pública

Dimensão 1 - Gestão Educacional;

Dimensão 2 - Formação de Professores e de Profissionais de Serviço e Apoio Escolar;

Dimensão 3 - Práticas Pedagógicas e Avaliação;

Dimensão 4 - Infraestrutura Física e Recursos Pedagógicos (BRASIL, 2007, p. 6).

A responsabilidade pelo elaboração do PAR é do Secretário de Educação correspondente, ou algum profissional por ele indicado. No entanto, em vários momentos dos documentos orientadores, é mencionada e proposta a importância da participação da comunidade escolar e da sociedade mais ampla nessa elaboração. A periodicidade de elaboração do PAR é de cinco anos, todavia ele pode ser renovado ou atualizado em períodos intermediários.

O registro do PAR é feito por meio de uma plataforma eletrônica denominada Sistema Integrado de Planejamento, Orçamento e Finanças (Simec). Segundo as orientações contidas no Manual do Usuário do Simec, esse sistema tem como objetivo captar e armazenar as propostas orçamentárias e o remanejamento de créditos de todas as unidades vinculadas ao Ministério da Educação. Para tanto, ele tem como principais características:

- $\quad$ Otimização do desenvolvimento das propostas orçamentárias e dos remanejamentos de créditos por meio de acompanhamento simultâneo da equipe de orçamento;

- Maior rapidez na recuperação de dados e elaboração instantânea do QDD - Quadro de Detalhamento de Despesa;

- Detalhamento da despesa no nível de natureza de despesa, fonte, identificador de uso e outros, de acordo com a funcional programática descrita no Manual Técnico do Orçamento; e

- Implantação de um ciclo de atualização das informações comparando informações de diferentes fases entre a proposta da unidade até a publicação da Lei (BRASIL, 2013, p. 3).

Orientado pelas quatro dimensões destacadas há pouco, o processo de elaboração PAR se divide em duas grandes etapas. A primeira etapa consiste na aplicação do instrumento para realização do diagnóstico da rede de ensino. A segunda etapa consiste na formulação do plano de ação propriamente dita.

Na fase de diagnóstico, a plataforma disponibiliza, de início, inúmeras informações relativas aos dados educacionais e demográficos da unidade 
federada (município, ou estado ou Distrito Federal). Desse modo, a equipe de elaboração do PAR tem em mãos uma série de dados atualizados referentes ao perfil de suas respectivas populações e redes de ensino, taxa de escolarização, taxa de analfabetismo, índice de desenvolvimento da infância, Índice de Desenvolvimento da Educação Básica (ldeb), resultado na Prova Brasil e no Exame Nacional do Ensino Médio (Enem), número de escolas e número de matrículas por modalidade e etapa de ensino, número de funções docentes, principais atividades econômicas, trajetória histórica, entre outros. Na verdade, é um conjunto de 23 tabelas que sintetizam essas informações.

Em seguida, ainda no processo de construção do diagnóstico da realidade em processo de planejamento, são propostas quinze questões chamadas de "pontuais" e que envolvem os seguintes aspectos: existência e forma de regulamentação do sistema, plano, conselho (municipal ou estadual ou distrital) de ensino, do Comitê Local do Compromisso Todos Pela Educação, do Conselho do Fundeb; do Conselho Escolar; do órgão responsável pela gestão dos recursos de manutenção e desenvolvimento do ensino; quantidade e dependência administrativa de creches e pré-escolas; critérios de escolha do diretor da escola; existência ou não de plano de carreira para o magistério e profissionais de serviços de apoio; relação da secretaria de educação com as instituições formadas de professores; avaliações educacionais; provinha Brasil e alfabetização de jovens e adultos.

Cada uma dessas questões demanda que o responsável pela sistematização do PAR, no Simec, abra diferentes ambientes (abas ou janelas) lance os dados e, gradativamente, preencha todos os campos.

Após essas questões pontuais, o instrumento passa a contemplar vários aspectos em torno das quatro dimensões que o estruturam. Dentro da Dimensão 1 - Gestão Educacional - são levantados e analisados dados relativos a quatro item: gestão democrática: articulação e desenvolvimento dos sistemas de ensino; gestão de pessoas; conhecimento e utilização de informação; gestão de finanças; comunicação e interação com a sociedade.

Na Dimensão 2 - Formação de Professores e de Profissionais de Serviço e Apoio Escolar - o instrumento procura coletar dados sobre a formação inicial e continuada dos professores da Educação Básica; formação de professores da Educação Básica para atuação em educação especial/ atendimento educacional especializado, escolas do campo, em comunidades 
Faces do gerencialismo em educação no contexto da nova gestão pública

quilombolas ou escolas indígenas; formação de professores da Educação Básica para cumprimento das Leis 9.795/99, 10.639/03, 11.525/07 e $11.645 / 08$ e, formação de profissionais da Educação e outros representantes da comunidade escolar.

Quanto à Dimensão 3 - Práticas Pedagógicas e Avaliação - as questões giram em torno da organização da rede de ensino; das práticas pedagógicas e da avaliação da aprendizagem dos alunos e tempo para assistência individual/coletiva aos alunos que apresentam dificuldade de aprendizagem.

Por último, na Dimensão 4 - Infraestrutura Física e Recursos Pedagógicos; quatro aspectos são considerados: Instalações físicas da secretaria municipal de educação; condições da rede física escolar existente; uso de tecnologias; recursos pedagógicos para o desenvolvimento de práticas pedagógicas que considerem a diversidade das demandas educacionais.

No contexto e em torno dessas quatro dimensões, tem-se um total de 82 indicadores, de modo que, para cada um deles, devem ser atribuídas uma pontuação de 01 a 04 , sendo que os indicadores com pontuação mais alta 103 e 04) se encontrariam em situação mais positiva e aqueles com pontuação mais baixa (01 e 02) se refeririam àquelas situações que demandariam ações mais imediatas de curto, médio e longo prazo.

Por sua vez, em torno de cada um desses indicadores, são disponibilizadas ações e subações resultantes e/ou articuladas a programas e projetos estruturados pelo MEC e suas respectivas Secretarias, ou por suas autarquias, especialmente o Fundo Nacional de Desenvolvimento da Educação (FNDE) e pela Coordenação de Aperfeiçoamento de Pessoal de Nivel Superior (Capes).

Em face do diagnóstico formulado e com base nas possibilidades de ações e subações disponibilizadas pelo MEC, passa-se, então, para a segunda etapa de elaboração PAR.

Nessa segunda etapa, cada ente federado deve informar no seu PAR o encaminhamento que será adotado referente a cada indicador. Esse encaminhamento pode ser no sentido de aderir a um determinado programa o projeto proposto pelo MEC e suas autarquias; ou solicitar apoio financeiro e/ ou técnico para implementação de alguma ação específica; ou, ainda, situar as ações locais que serão desenvolvidas em cada dimensão considerada no processo de planejamento. 
O PAR, elaborado e encaminhado pelo município, estado ou Distrito Federal, deve ser elaborado considerando um planejamento para um período de cinco anos. Mas periodicamente, de modo geral, a cada ano, o município pode apresentar atualizações em seu diagnóstico e nas propostas e demandas inicialmente colocadas. É a partir dele que o Minsitério da Educação, por meio de seus órgãos internos, tem se orientado para a implementação de apoio técnico e/ou financeiro aos entes federados. Além disso, na medida em que o PAR e sua implementação estão registrados no Simec, torna-se possível que esse Ministério acompanha e monitore, permanentemente, o desenvolvimento das ações apoiadas em cada um desses entes.

De outra parte, a plataforma eletrônica do Simec, por meio da qual se realiza a elaboração do PAR, não oferece muita flexibilidae e alternativas aos governos locais quanto às ações e atividades que serão demandadas, justamente porque, como foi apresentado, há pouco, é o próprio sistema que vai indicando, diante dos problemas diagnosticados, as propostas de ação a serem desenvolvidas. Como as questões, por meio das quais se estrutura o diagnóstico da rede de ensino, são extremamente abrangentes e em grande número, isto acaba por induzir a própria avaliação que se realiza no processo de diagnóstico dessa rede. Nesse sentido, ainda que o munípio, estado, Distrito Federal, tenham autonomia e liberdade para proceder à avaliação diagnóstica de sua realidade, a ferramenta e a tecnologia que ela carrega formatam, padronizam, homogenizam essa avaliação. Isso coloca em questão o grau e o tipo autonomia que os governos locais têm condições de realizar e construir nos processos de gestão das respectivas redes de ensino.

\section{Conclusões}

Ao final deste estudo, é possível apreender algumas das dimensões, significados e faces do PAR no contexto das políticas educacionais implementadas ao longo de 2007 a 2014.

Por um lado, traz consigo elementos do planejamento estratégico aplicados ao campo da gestão dos sistemas educacionais, introduzindo uma metodologia de planejamento que tem como marcas a centralidade na equipe gestora, ao mesmo tempo que todo o processo está calcado em aspectos técnicos, que secundarizam as questões políticas, culturais e institucionais que 
Faces do gerencialismo em educação no contexto da nova gestão pública

engrendram a realidade desses sistemas e suas escolas. A plataforma eletrônica, por meio da qual o PAR é elaborada, não abre a possibililidade para que tais questões sejam problematizadas.

Além disso, a perspectiva da avaliação adotada se restringe a identificar os pontos fortes e os pontos fracos, sendo que os primeiros seriam assinalados ao se atribuir uma pontuação 3 ou 4 para cada indicador destacado, enquanto os pontos fracos seriam identificados com a atribuição da pontuação 1 ou 2. Essa perspectiva de análise fragmenta e impossibilita que se construa uma visão mais ampla da realidade educacional.

Por outro lado, por meio do PAR, é possível apreender fortes elementos do governo eletrônico analisado ao longo deste trabalho. Sem dúvida, à medida que sua elaboração e registro ocorrem por meio da plataforma eletrônica do Simec, ele acaba incorporando o uso das tecnologias da informação e comunicação no processo de planejamento. Mas, ao mesmo tempo, na medida em que isso ocorre, também se abre a possibilidade de um acompanhamento mais sistemático e imediato deste planejamento e de sua implementação.

Com efeito, por meio do ambiente virtual do PAR na plataforma Simec, os gestores da educação, especialmente aqueles responsáveis pelos sistemas de ensino e pelos órgãos centrais da educação, têm condições de realizar um monitoramento sistemático e permanente das ações e da realidade de cada ente federado que apresentou seu Plano no Simec. Nesse sentido, o PAR, no contexto do governo eletrônico estendido à gestão da educação, acaba por se constituir em uma importante ferramenta de controle, monitoramento e acompanhamento na formulação e implementação de políticas educacionais no âmbito dos governos locais.

Nesse sentido, o governo central, mesmo sem estabelecer normas e regras gerais cria, em relação ao governos locais, um importante instrumento de regulação e controle das políticas educacionais colocadas em curso. Concomitante à implementação de sistemas nacionais e centralizados de avaliação, também o planejamento, organizado em plataformas eletrônicas padronizadas, como a plataforma do Simec em que é apresentado o PAR, ajuda a definir os contornos da nova regulação na condução das políticas públicas no campo da educação.

Delineiam-se, desse modo, os contornos da NGP, porém, agora, com seus tentáculos estendidos para o campo educacional. Nesse movimento, 
tem-se, igualmente, o aprofundamento do gerencialismo na educação, fazendo com que a gestão da educação assuma um caráter cada vez mais burocrático, padronizado, fragmentado da organização da educação, com a utilização cada vez mais recorrente de mecanismos e ferramentas gerenciais oriundas do setor privado da produção. Uma gestão voltada para a busca da eficiência e da eficácia mensurada por meio de resultados alcançados em avaliações de caráter geral sustentadas nos chamados testes padronizados. Essa perspectiva gerencial conduz a gestão da educação e a busca da qualidade no campo educativo para os limites de uma perspectiva reducionista dos processos educativos, não dialogada com a formação integral do indivíduo, voltada para a construção e exercício da cidadania e da autonomia.

Têm-se, portanto, mais algumas faces do gerencialismo na educação.

\section{Referências}

AFONSO, Almerindo. Janela. Avaliação educacional: regulação e emancipação. São Paulo: Cortez, 2005.

AFONSO, Almerindo Janela. Políticas avaliativas e accountability em educação - subsídios para um debate iberoamericano. Revista de Ciências da Educação, São Paulo, n. 9, p. 57-70. maio/ago. 2009.

AFONSO, Almerindo Janela. Para uma conceitualização alternativa de accountability em educação. Educação \& Sociedade, Campinas, v. 33, n. 1 19, p. 471-484, abr./jun. 2012.

AGUNE, Roberto Meizi; CARLOS, José Antônio. Governo eletrônico e novos processos de trabalho. In: LEVY, Evelyn; DRAGO, Pedro Aníbal (Org.). Gestão pública no Brasil contemporâneo. São Paulo: FUNDAP, 2005.

ANDERSON, Perry. Balanço do Neoliberalismo. In: SADER, Emir; GENTILI, Pablo (Org.). Pós-neoliberalismo: as políticas sociais e o Estado democrático. Rio de Janeiro: Paz e Terra, 1995.

BARROSO, João. $\bigcirc$ estado, a educação e a regulação das políticas públicas. Educação \& Sociedade, Campinas, v. 26, n. 92, p. 726-751, out. 2005.

BRASIL. Lei n. 9.795, de 27 de abril de 1999. Dispõe sobre a educação ambiental, institui a Políitica Nacional de Educação Ambiental e dá outras providências. Brasília (DF): Imprensa 
Faces do gerencialismo em educação no contexto da nova gestão pública

Nacional, 1999. Disponível em: http://www.planalto.gov.br/ccivil_03/leis/19795.htm. Acesso em: 15 fev. 2014.

Lei $\mathbf{n}^{\circ}$ 10.639, de 09 de janeiro de 2003. Altera a Lei n9.394, de 20 de dezembro de 1996, que estabelece as diretrizes e bases da educação nacional, para incluir no currículo oficial da Rede de Ensino a obrigatoriedade da temática "História e Cultura AfroBrasileira", e dá outras providências. Brasília (DF): Imprensa Nacional, 2003. Disponível em: http://www.planalto.gov.br/ccivil_03/leis/2003/110.639.htm. Acesso em: 15 fev. 2014.

Lei $\mathbf{n}^{\circ} \mathbf{1 1 . 5 2 5}$, de 25 de setembro de 2007. Acrescenta $\S 5^{\circ}$ ao art. 32 da Lei $n$. 9.394, de 20 de dezembro de 1996, para incluir conteúdo que trate dos direitos das crianças e adolescentes no currículo do ensino fundamental. Brasília (DF): Imprensa Nacional, 2007. Disponível em: http://www.planalto.gov.br/ccivil_03/_Ato2007-2010/2007/ Lei/L1 1525.htm. Acesso em: 15 fev. 2014.

Lei $\mathbf{n}^{\circ}$ 11.645, de 10 de março de 2008. Altera a Lei no 9.394, de 20 de dezembro de 1996, modificada pela Lei no 10.639, de 9 de janeiro de 2003, que estabelece as diretrizes e bases da educação nacional, para incluir no currículo oficial da rede de ensino a obrigatoriedade da temática "História e Cultura Afro-Brasileira e Indígena." Brasília (DF): Imprensa Nacional, 2008. Disponível em: http://www.planalto.gov.br/ccivil_03/_ ato2007-2010/2008/lei/l1 1645.htm. Acesso em: 15 fev. 2014.

Ministério da Administração Federal e da Reforma do Estado. Plano Diretor da Reforma do Aparelho do Estado. Brasília (DF), 1995. Disponível em: http://www. bresserpereira.org.br/documents/mare/planodiretor/planodiretor.pdf. Acesso em: 12 fev. 2014.

Decreto $n^{\circ}$ 6.094, de 24 de abril de 2007. Dispõe sobre a implementação do plano de metas compromisso todos pela educação, pela união federal, em regime de colaboração com municípios, distrito federal e estados, e a participação das famílias e da comunidade, mediante programas e ações de assistência técnica e financeira, visando a mobilização social pela melhoria da qualidade da educação básica. Diário Oficial [da] União, Poder Executivo, Brasília, DF, 25 abr. 2007. Seção 1, p. 5.

Ministério da Educação. Manual do usuário do SIMEC. 2008. Disponível em: http://simec.mec.gov.br/. Acesso em: 10 dez. 2013.

CAMPOS, Vicente Falconi. TQC: controle da qualidade total (no estilo japônes). Belo Horizonte: Fundação Christiano Ottoni, 1992. 
CASTRO, Alda Maria Duarte Araújo. Administração gerencial: a nova configuração da gestão da educação na América Latina. Revista Brasileira de Política e Administração da Educação, Porto Alegre, v. 24, n. 3, p. 389-406, set./dez. 2008.

DINIZ, Eduardo Henrique; BARBOSA, Alexandre Fernandes; JUNQUEIRA, Alvaro Ribeiro Botelho Junqueira; PRADO, Otavio Prado. O governo eletrônico no Brasil: perspectiva histórica a partir de um modelo estruturado de análise. Revista Brasileira de Administração Pública, Rio de Janeiro, v. 1, n. 43, p. 23-48, jan./fev. 2009.

GÓMES, José Maria. Globalização, Estado-nação e cidadania. In: GÓMES, José Maria (Org.). Política e democracia em tempos de globalização. Petrópolis (RJ): Vozes; Buenos Aires: CLACSO; Rio de Janeiro: LPP - Laboratório de Políticas Públicas, 2000.

HYPOLITO, Álvaro Moreira. Estado gerencial, reestruturação educativa e gestão escolar. Revista Brasileira de Política e Administração da Educação, Porto Alegre, v. 27, n. 1, p. 63-78, jan./abr. 2008.

Políticas curriculares, Estado e regulação. Educação \& Sociedade, campinas, v. 31 , n. 113, p. 1337-1354, out./dez., 2010.

Gestão do trabalho docente e qualidade da educação. Disponível em: http:// www.anpae.org.br/congressos_antigos/simposio2007/16.pdf. Acesso em: 3 ago. 2014.

MACHADO, Lucília Regina de Sousa. Controle da Qualidade Total: Uma nova gestão do trabalho, uma nova pedagogia do capital. In: FIDALGO, Fernando Selmar; MACHADO, Lucília Regina de Sousa (Org.). Controle da qualidade total - uma nova pedagogia do capital. Belo Horizonte: Movimento de Cultura Marxista, 1994.

MAUÉS, Olgaíses. Regulação educacional, formação e trabalho docente. Estudos em avaliação Educacional, São Paulo, v. 20, n. 44, 2009. Disponível em: http://www.fcc.org. br/pesquisa/publicacoes/eae/arquivos/1532/1532.pdf. Acesso em: 3 set. 2012.

MEDEIROS, Paulo Henrique Ramos. Governo eletrônico no Brasil: Aspectos institucionais e reflexos na governança. 2004. 31 8f. Dissertação (Mestrado em Administração) - Programa de Pós-Graduação em Administração, Brasília, Universidade de Brasília, 2004.

MEDEIROS, Paulo Henrique Ramos; GUIMARÃES, Tomás de Aquino. $\bigcirc$ estágio do governo eletrônico no Brasil em relação ao contexto mundial. Revista do Serviço Público, Brasília, v. 55, n. 1/2, p. 49-66, jan./jun. 2004. 
Faces do gerencialismo em educação no contexto da nova gestão pública

OLIVEIRA, Dialma de Pinho Rebouças de. Estratégia empresarial: uma abordagem empreendedora. São Paulo: Atlas, 1991.

OLIVEIRA, Dalila Andrade. Educação básica: gestão do trabalho e da pobreza. Petrópolis: Vozes, 2001.

Regulação das políticas educacionais na América Latina e suas consequências para os trabalhadores docente. Educação \& Sociedade, Campinas, v. 26, n. 92, p. 753-776, out. 2005.

OSBORNE, David. Banishing bureaucracy: the five strategies for reinventing government. New York: Plume, 1997.

PARENTE FILHO, José. Planejamento estratégico na educação. Brasília: Plano Editora, 2001.

PAULA, Ana Paula Paes de. Por uma nova gestão pública: limites e potencialidades da experiência contemporânea. Rio de Janeiro: Editora FGV, 2005.

PERONI, Vera. Política Educacional e papel do Estado no Brasil dos anos 1990. São Paulo: Xamã, 2003.

238 PRADO, Otavio; PÓ, Marcos Vinicius. Limites e possibilidades do governo eletrônico na accountability: uma exploração de portais governamentais frente às teorias da democracia. In: ENCONTRO ANUAL DA ANPOCS, 34; 2010, Caxambu. Anais... Caxambu (MG): Associação Nacional de Pós-Graduação e Pesquisa em Ciências Sociais, 2010.

RAMOS, Sérgio. Tecnologias de informação e comunicação: conceitos básicos. Escola Dr. Mário Sacramento, Aveiro, Portugal, 2008.

RONAGHAN, S. Benchmarking e-government: a global perspective. assessing the progress of the UN member states. United Nations Division for Public Economics and Public Administration \& American Society for Public Administration, May, 2002.

SALDANHA, Clezio. Introdução à gestão pública. São Paulo: Saraiva, 2006.

VALENTE, Lucia. Permanências e mudanças na organização do trabalho escolar nas Geraes: uma análise do programa dinheiro direto na escola (PDDE) e do PDE-Escola. 2011. 202 f. Tese (Doutorado em Educação) - Programa de Pós-Graduação em Educação, Universidade Federal de Uberlândia, Uberlândia, 2011.

VIDAL, Eloisa Maia; VIEIRA, Sofia Lerche. Gestão educacional e resultados no ldeb: um estudo de caso em 10 municípios cearenses. In: REUNIÃO DA ASSOCIAÇÃO BRASILEIRA 
DE AVALIAÇÃO EDUCACIONAL, 6; 201 1, Fortaleça. Anais... Fortaleza: Associação Brasileira de Avaliação Educacional, 2011.

VIEIRA, Sofia Lerche. Continuidades e rupturas na política educacional: indicadores do período 1995-2005. In: REUNIÃO ANUAL DA ANPED, 34; 201 1, Natal. Anais... Natal: Associação Nacional de Pós-Graduação e Pesquisa em Educação, 2011.

Prof. Dr. Marcelo Soares Pereira da Silva Universidade Federal de Uberlândia Faculdade de Educação Grupo de Pesquisa Pólis | Grupo de Estudos e Pesquisas em Políticas, Educação e Cidadania E-mail | marcelospsilva@hotmail.com.

Profa. Ms. Lorena Sousa Carvalho Universidade Federal de Uberlândia Escola de Educação Básica Grupo de Pesquisa Pólis | Grupo de Estudos e Pesquisas em Políticas, Educação e Cidadania E-mail | lorenasoucar@yahoo.com.br.

Recebido 10 nov. 2014 Aceito 27 fev. 2015 